\title{
Coleta seletiva no Brasil: uma análise bibliométrica de 2000 a 2021
}

\author{
Selective collection in Brazill: a bibliometric analysis from 2000 to 2021 \\ Colección selectiva en Brasil: un análisis bibliométrico de 2000 a 2021
}

Recebido: 05/11/2021 | Revisado: 11/11/2021 | Aceito: 16/11/2021 | Publicado: 26/11/2021

\author{
Magno Alves Ribeiro \\ ORCID https://orcid.org/0000-0003-3101-9903 \\ Universidade do Estado de Mato Grosso, Brasil \\ E-mail: magnoalves@unemat.br \\ Liliane Cristine Schlemer Alcântara \\ ORCID https://orcid.org/0000-0001-8502-720X \\ Universidade do Estado de Mato Grosso, Brasil \\ E-mail: lilianecsa@yahoo.com.br \\ Carlos Alberto Cioce Sampaio \\ ORCID https://orcid.org/0000-0002-0664-0266 \\ Universidade do Estado de Mato Grosso, Brasil \\ Universidade do Sul de Santa Catarina, Brasil \\ E-mail: carlos.cioce@gmail.com \\ Sandro Benedito Sguarezi \\ ORCID https://orcid.org/0000-0001-7361-8977 \\ Universidade do Estado de Mato Grosso, Brasil \\ E-mail: sandrosguarezi@gmail.com
}

\begin{abstract}
Resumo
A coleta seletiva de materiais recicláveis é um importante fator para proteção do meio ambiente e desenvolvimento econômico e social dos catadores de materiais recicláveis. O objetivo da pesquisa foi apresentar o estado da arte da coleta seletiva de materiais recicláveis no Brasil. Trata-se de uma pesquisa descritiva com abordagem quantitativa, que utilizou técnicas bibliométricas. Para obtenção dos artigos analisados, foram realizadas buscas na base de dados Periódicos CAPES, com o termo "Coleta Seletiva" e Brasil no título, resumo, palavras-chave, resultando em uma amostra de 447 artigos, para o período de 2000 a 2021. Os resultados apresentados demonstram que a curva de maiores publicações ocorreu no ano 2015 e que as praças de maiores publicações estão concentradas na região Sudeste do Brasil, sendo que o periódico que mais publicou foi a Revista Monografias Ambientais. As palavras-chave mais citadas foram public health, recycling, environmental education, além da palavra Brasil.
\end{abstract}

Palavras-chave: Catadores; Resíduos sólidos; Materiais recicláveis; Logística reversa.

\begin{abstract}
The selective collection of recyclable materials is an important factor for environmental protection and economic and social development of recyclable material collectors. The research aims to present the state of the art of a selective collection of recyclable materials in Brazil. The approach is qualitative and refers to descriptive research from bibliometric techniques by the CAPES Journal database. The search with the term "Selective Collection" and "Brazil" in the title, abstract, keywords, resulted in a sample of 447 articles between 2000 and 2020. Show up the curve of the largest publications that occurred in 2015 as also the squares of publications are concentrated in the Southeast region of Brazil. The journal that was most published was the Environmental Monographs. The most cited keywords were public health, recycling, environmental education, in addition to the word Brazil.
\end{abstract}

Keywords: Collectors; Solid waste; Recyclable materials; Reverse logistic.

\section{Resumen}

La recogida selectiva de materiales reciclables es un factor importante para la protección del medio ambiente y el desarrollo económico y social de los recolectores de materiales reciclables. El objetivo de la investigación fue presentar el estado del arte de la recolección selectiva de materiales reciclables en Brasil. Se trata de una investigación descriptiva con enfoque cuantitativo, que utilizó técnicas bibliométricas. Para la obtención de los artículos analizados se realizaron búsquedas en la base de datos de Revistas CAPES, con el término "Colección Selectiva" y Brasil en el título, resumen, palabras clave, dando como resultado una muestra de 447 artículos, para el período 2000 a 2020. Los resultados presentados muestran que la curva de mayores publicaciones ocurrió en 2015 y que las plazas de mayores publicaciones se concentran en la región sureste de Brasil, siendo la revista que más se publicó Environmental 
Monographs. Las palabras clave más citadas fueron salud pública, reciclaje y educación ambiental, además de la palabra Brasil.

Palabras clave: Recolectores; Residuos sólidos; Materiales reciclables; Logística inversa.

\section{Introdução}

O tema coleta seletiva de materiais recicláveis por tempo ficou invisível aos olhos do poder público de qualquer esfera. Os catadores viviam a margem da sociedade e eram vistos como problema nos grandes centros urbanos e ainda muitas vezes vistos pela sociedade como "delinquentes" e/ou "mendigos" (Pereira \& Teixeira, 2011). As primeiras experiências associativas de catadores iniciaram-se em Porto Alegre, Belo Horizonte e São Paulo, cuja criação da associação dos catadores de papel ocorreu em 1986, com apoio de organizações da igreja católica (Cempre, 2013; Miranda; Mattos, 2018; Conke \& Nascimento, 2018).

Alguns municípios praticam a coleta seletiva, desde a década de 1990, no âmbito da gestão integrada de resíduos sólidos, com iniciativas de prefeituras municipais, empresas contratadas ou organizações de catadores. Dentre os vários movimentos que foram se organizado por todo país, o Movimento Nacional dos Catadores de Materiais Recicláveis surgiu, em meados de 1999, com o 1. ${ }^{\circ}$ Encontro Nacional de Catadores de Papel, buscando organizar catadores em todo país, impingindo os aspectos da valorização da classe, além dos princípios de autogestão, solidariedade, apoio mútuo, etc., contudo, antes mesmo deste primeiro encontro, catadores impulsionavam a luta por direitos em diversas regiões do Brasil (MNCR, 2019).

A profissão 'catador de materiais recicláveis' acabou sendo reconhecida, em 2002, pelo Ministério do Trabalho e Emprego (MTR) (Besen et al., 2014). Em que pese o reconhecimento da profissão no mercado formal de trabalho, a coleta seletiva, deriva-se como um subemprego, em virtude da necessidade de sobrevivência imediata, a catação se desenvolve nas áreas urbanas das cidades brasileiras, submetendo-se a exploração por parte de empresários ou atravessadores que compram o material por valor abaixo do preço justo (Silva \& Zanin, 2017; Gutierrez \& Zanin, 2011).

Efetivamente como política pública, o processo de coleta seletiva e a inclusão social dos catadores, somente tornou-se realidade com a promulgação da lei 11.445/2007 que estabeleceu as diretrizes nacionais para o saneamento básico, e permitiu as prefeituras contratarem serviços de coleta, processamento e comercialização de resíduos sólidos urbanos recicláveis ou reutilizáveis, com dispensa de licitação de associações e cooperativas.

Em 2010, foi aprovada a lei federal 12.305/2010 sobre a Política Nacional de Resíduos Sólidos (PNRS). Esta lei tornou-se importante instrumento na adoção das diretrizes que trata da gestão integrada e do gerenciamento de resíduos sólidos, adotando responsabilidades aos geradores de resíduos, ao poder público, bem como os instrumentos econômicos e as dimensões ligadas ao aspecto social, ambiental, cultural, etc (Lei n. 12.305, 2010).

A legislação tratou ainda de conceituar termos como ciclo de vida, coleta seletiva, gerenciamento e gestão integrada de resíduos sólidos, logística reversa, reciclagem, resíduos sólidos entre outros, ofertando também aos entes da federação os instrumentos necessários a implantação dos planos de resíduos, coleta seletiva e opção para incentivar a criação de cooperativa dos catadores. Componentes importantes na ocasião que são implantados, a gestão dos resíduos sólidos nos municípios pode garantir uma gestão ambiental com proteção da saúde coletiva e do meio ambiente equilibrado.

Como instrumento para organizar e planejar a gestão e o gerenciamento de resíduos sólidos no país, a lei 12.305/2010, incumbiu aos Estados e Municípios a promover a integração, organização, planejamento e execução dos resíduos em seus aglomerados, controlando e fiscalizando as atividades geradoras de resíduos sob a sua competência.

A legislação fixou ainda a necessidade de elaboração de um plano nacional para gestão dos resíduos e em consequência, planos estaduais e municipais. Os planos têm o dever de observar uma ordem de prioridade quanto a não geração de resíduos, metas para redução, reutilizar e reciclar e por derradeiro o tratamento dos resíduos de maneira ambientalmente adequada. A incumbência de tal gestão, acaba ficando a cargo dos municípios, com controle e fiscalização de 
órgãos federal e estadual, observando aspectos e conceitos dos resíduos como os domiciliares, limpeza urbana, resultantes de comércio/indústria, construção civil, transportes, agropastoril, entre outros.

Como planejamento relacionado ao destino dos resíduos sólidos gerados, a União elabora um plano com vigência de 20 anos, sendo atualizado a cada 4 anos. A mesma incumbência também cabe aos estados com o mesmo horizonte de atuação e revisão quadrienal, com as mesmas metas de diagnósticos, proposição de cenários, metas de redução, de reutilização, reciclagem, entre outros.

Cabe finalmente aos municípios a elaboração do seu planejamento municipal de gestão integrada, o que além dos benefícios, afeto ao meio ambiente e social, é uma condição para eventual acesso a recursos da união destinados a empreendimentos e serviços relacionados a limpeza urbana e manejo dos resíduos. A prioridade aos recursos caberá aos municípios que implantarem a coleta seletiva, com participação de cooperativas ou associações de catadores de materiais reutilizáveis, ou recicláveis.

Neste contexto, o estudo objetivou apresentar o estado da arte da coleta seletiva de materiais recicláveis no Brasil. O mapeamento dos artigos publicados sobre coleta seletiva possibilita melhor compreensão de como a academia e o poder público tratam essa temática. Além de oportunizar contribuição ambiental e social: despertando a consciência da população e gerando informações úteis para subsidiar a tomada de decisão dos gestores quanto ao aperfeiçoamento de metodologias já utilizadas no processo de coleta seletiva, bem como a criação de novas políticas públicas.

\section{Revisão de Literatura}

A coleta seletiva consiste na prática de gestão de resíduos, exercida por meio de sistema de recolhimento diferenciado, que separa previamente papéis, plásticos, vidros, metais e resíduos orgânicos, cuja disposição pode ocorrer em postos de entrega voluntária, postos de troca, de porta em porta, com agendamento prévio em dias acertados com as repartições públicas, indústrias e comércio, com a participação de catadores, sucateiros ou instituições beneficentes (Bringhenti, 2004; Moraes, 2011).

No Brasil, a coleta seletiva de materiais recicláveis era uma realidade mesmo antes da aprovação da Política Nacional de Resíduos Sólidos - PNRS (Lei n. 12.305, 2010). Após este marco legal, houve avanços, embora aquém do ideal, as modalidades de coleta seletiva contribuíram nos aspectos, ambiental, social e humano na sustentabilidade da vida urbana e até rural, com as coletas específicas.

Com a aprovação da PNRS e o estabelecimento de metas para redução dos resíduos sólidos recicláveis em aterros sanitários, a coleta seletiva de recicláveis ganhou relevância e maior cuidado por parte das autoridades. Trata-se de atividades interdependentes e que podem contribuir efetivamente na sustentabilidade urbana e na economia de recursos naturais, reduzindo consequentemente a emissão dos gases de efeito estufa - GEE (Besen et al., 2014).

O Sistema Nacional de Informações sobre Saneamento (SNIS), que está ligado ao Ministério de Desenvolvimento Regional (MDR), tem apresentado, desde 2002, um diagnóstico do manejo de resíduos sólidos de todo país (MDR, 2019). A partir das informações apresentadas, é possível conhecer e aprofundar nos dados analíticos da coleta seletiva do Brasil.

A primeira publicação do diagnóstico, em 2002, abrangeu uma amostra de 109 municípios, o que representava 31,6\% da população brasileira. Na época registrava-se 34 empreendimentos organizados de coleta seletiva de resíduos recicláveis, promovidos por prefeituras, associações, cooperativas entre outros. Nesta amostra, a massa de resíduos reaproveitáveis recuperados foi de 49.634 toneladas (t) de papel e papelão, 40.013t de plásticos, 18.720t de metais diversos, $11.438 \mathrm{t}$ de vidros e 10.155 de outros materiais, totalizando 129.960 toneladas (MDR, 2019). 
Em 2017, foi realizado pelo Ministério do Desenvolvimento Regional um diagnóstico sobre a coleta de resíduos no Brasil abrangendo 3.556 municípios participantes, correspondendo a 63,8\% dos municípios brasileiros e 83,9\% da população do país. A cobertura do serviço de coleta de resíduos atinge 98,8\% da população (MDR, 2019)

No tocante a coleta seletiva, a pesquisa abrangeu 1.256 municípios ou 22,5\% do universo Brasileiro. Contudo, quando comparada a coleta dos resíduos sólidos e a coleta de resíduos reaproveitáveis, foi identificado que o volume de resíduos coletados era de 50,8 milhões de toneladas, equivalente a uma média per capita de $0,95 \mathrm{~kg} / \mathrm{hab} / \mathrm{dia}$ ou $347 \mathrm{~kg} / \mathrm{hab} / \mathrm{ano}$, enquanto a massa de recicláveis foi de 13,7 kg/hab/ano, equivalente a 1,5 milhão de toneladas de material reciclável (MDR, 2019). Assim, tendo em vista que, em 2002, a coleta seletiva foi de 129t, constata-se, um crescimento significativo.

Apesar de parecer incipiente, observando os dados do diagnóstico de 2002 (ainda que no início a amostra não representava o mesmo índice do universo em 2019), o modelo de coleta apresentou evolução importante, onde em 2002 a coleta registrada foi de 129 t. Em 2017, atingiu 1,5 milhões de toneladas.

A lei de resíduos sólidos tornou-se importante instrumento na adoção das diretrizes que trata da gestão integrada e do gerenciamento de resíduos sólidos, adotando responsabilidades aos geradores de resíduos, ao poder público, bem como os instrumentos econômicos e as dimensões que alcança, no aspecto social, ambiental, cultural. Traz como instrumentos da Política Nacional de Resíduos Sólidos, entre outros, os planos, a coleta seletiva, os sistemas de logística reversa, o incentivo à criação de cooperativas e/ou associação de catadores, metas para eliminação de lixões e a inclusão social e à emancipação econômica dos catadores (Lei n. 12.305, 2010).

\section{Metodologia}

A pesquisa possui natureza descritiva, bibliométrica, caracterizando-se um estado da arte, com abordagem quantitativa. As pesquisas descritivas buscam investigar, analisar, registrar e classificar os fatos ou fenômenos sem a interferência do pesquisador (Richardson et al., 2012). As pesquisas bibliométricas tem como característica quantificar a produção científica e a sua finalidade é alcançada mediante a aplicação de uma técnica capaz de medir a influência dos pesquisadores ou periódicos, permitindo traçar o perfil e suas tendências, além de evidenciar áreas temáticas (Oliveira et al., 2013).

Pesquisa do tipo estado da arte tem a finalidade de conhecer as particularidades e tendências do campo de conhecimento por meio da produção acadêmica, além de permitir uma divulgação mais vasta e adequada, pode avaliar a qualidade da produção científica, a coerência entre os objetivos da pesquisa e seus delineamentos metodológicos (Megid Neto, 2009). É quantitativa porque têm como característica quantificar tanto a coleta quanto o tratamento dos dados, por meio de técnicas simples, como percentual, média, fluxo de caixa e outras (Richardson, 2012).

Como ferramenta metodológica a revisão da literatura pode produzir uma base de conhecimento confiável, gerenciando uma diversidade de conhecimentos já existentes, mapeando esta massa de informações de maneira organizada, com critérios e utilizando-se de etapas do que se pretende realizar. A revisão sistemática é composta basicamente por três estágios: planejamento da revisão, execução da revisão, divulgação e disseminação dos resultados (Tranfield, 2003).

As fases de elaboração da pesquisa envolveram cinco etapas, conforme resumo apresentado na figura 1 . A primeira etapa consistiu na escolha da base de dados e do software. Para identificar as tendências na literatura sobre a coleta seletiva, optou-se pela investigação na base de dados da Coordenação de Aperfeiçoamento de Pessoal de Nível Superior (CAPES). 
Figura 1 - Etapas da pesquisa.

\begin{tabular}{|c|c|c|c|c|}
\hline $\begin{array}{l}\text { ETAPA } 1 \text { Escolha } \\
\text { da base de dados e } \\
\text { do software. }\end{array}$ & $\begin{array}{l}\text { ETAPA 2 } \\
\text { Definição da } \\
\text { amostra de } \\
\text { pesquisa. }\end{array}$ & $\begin{array}{l}\text { ETAPA } 3 \text { Coleta } \\
\text { de dados na base. }\end{array}$ & $\begin{array}{l}\text { ETAPA } 4 \\
\text { Tratamento } \\
\text { bibliométrico dos } \\
\text { dados. }\end{array}$ & $\begin{array}{l}\text { ETAPA } 5 \text { Análise } \\
\text { dos dados. }\end{array}$ \\
\hline
\end{tabular}

Fonte: Elaborado pelos autores (2021)

Com relação ao software, utilizou-se $o$ EndNote que é um software de gerenciamento de referências bibliográficas, que possibilita salvar os arquivos de trabalho tanto nos computadores de uso pessoal quanto na rede (Internet) por meio do EndNote Web (Yamakawa et al., 2014), no qual os meta dados com extensão RIS foram arquivados. Para construção e visualização de redes bibliométrica, utilizou-se do software VOSviewer, que possibilita incluir, por exemplo, periódicos, pesquisadores ou publicações individuais, e podem ser construídas com base em relações de citação, acoplamento bibliográfico, cocitação ou coautoria (Van Eck; Waltman, 2010).

A segunda e terceira etapa versaram sobre a amostra da pesquisa e coleta dos dados. O critério na busca dos documentos indexados na base CAPES foi por assunto, com a inserção do termo "coleta seletiva" e mais a palavra "Brasil", de maneira que o resultado da busca nos títulos, resumos e palavras-chave tivessem relação com as pesquisas realizadas no Brasil. O recorte temporal foi do ano 2000 ao ano de 2021, até a data da extração (30/06/2021), tendo como resultado final 447, artigos sendo destes, 360 disponíveis online, e baixados em arquivos .pdf, via aplicativo Endnote 199.

A quarta etapa compreendeu a tabulação dos dados descritivos como autores, filiação (universidade de origem) e região demográfica etc., com o uso do software Excel, com base na amostra coletada. Para tratamento dos dados e a elaboração das redes bibliométricas, utilizou-se o software VOSViewer. Por fim, na última etapa, os dados foram analisados e mapeados por meio da investigação de redes de coautoria, de cocitação, de acoplamento bibliográfico e de coocorrência de palavraschave.

\section{Resultados e Discussão}

O software VOSviewer oferece diversas formas de visualizar os resultados da pesquisa em forma de figuras. A Figura 2 demostra a formação de clusters entre os autores que produziram artigos que tratam da coleta seletiva.

Quanto mais finas as linhas (arestas) de ligação, menos forte é a ligação (laços). Tão maiores os pontos (nós), mais relevância eles possuem. As relações formam clusters (grupos que se formam por afinidade ou proximidade) pela quantidade de publicações e força dos links de publicações de autores e coautores, e as cores aproximam os autores. 
Figura 2 - Rede de conexão de termos.

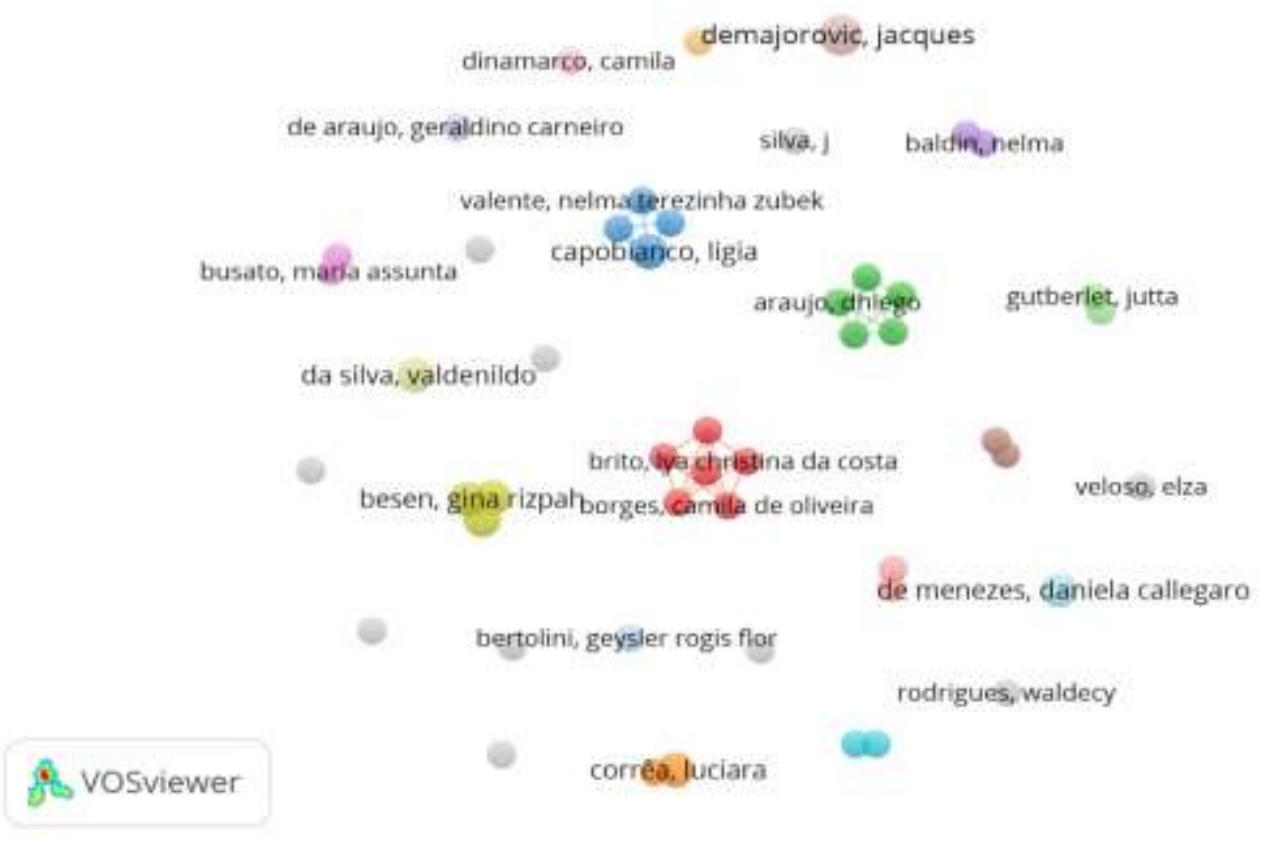

Fonte: Dados da pesquisa (2021)

Nesta rede de visualização, o software identificou 29 clusters, sendo o principal com seis autores, onde destaca: Borges, Ana Paula Aparecida; Borges, Camila de Oliveira; Brito, Iya Christina da Costa; Dos Santos, Dayane Graciele; Marciano, Eloah da Paixão; Nunes, Simara Maria Tavares, formando o principal cluster na cor vermelha.

Em continuação as análises, apresenta-se a figura 3, que trata das palavras que mais aparecem nos artigos, e assim são considerados na contagem das palavras. O programa calcula uma relevância para cada um dos termos apontados e que tiveram conexões entre os artigos.

Figura 3 - Palavras que mais aparecem nos artigos.

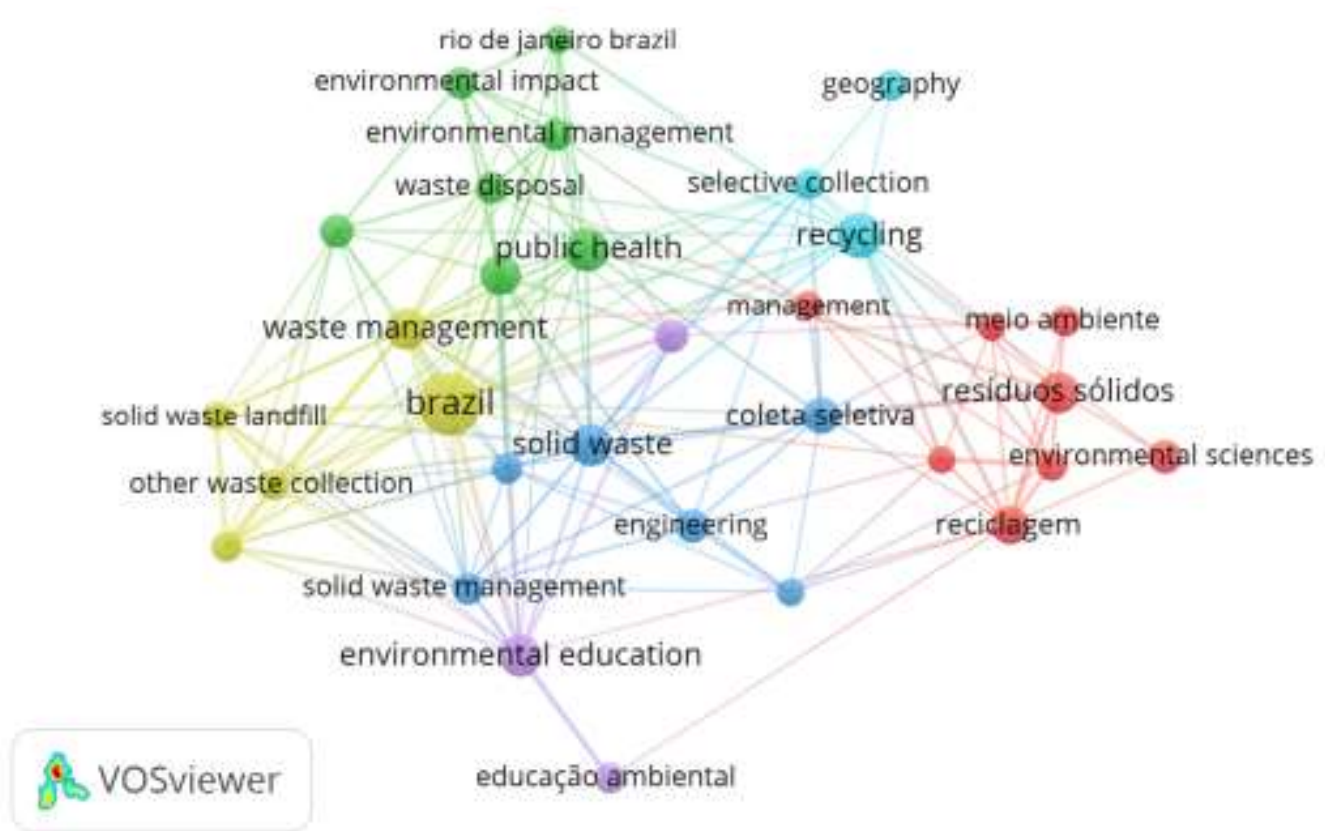

Fonte: Dados da pesquisa (2021). 
O software faz análise das palavras que mais aparecem nos artigos, para que esses sejam considerados na contagem. O programa calcula uma relevância para cada um dos termos apontados e que tiveram conexões entre os artigos. Na visualização 'Network Visualization' (rede de conexão dos termos), as mais relevantes como brazil, solid waste, recycling, public health, foram os grupos que se formaram por afinidade ou proximidade.

Na prática, a relevância das palavras tem uma importância ainda maior, já que os resíduos sólidos no Brasil influenciam diretamente na saúde pública, pois poluem rios e lençóis freáticos e outros ambientes. Uma gestão eficiente no manejo dos resíduos diminui o impacto, além de que a reciclagem reduz o volume descartado e ainda gera trabalho e renda aos trabalhadores. O software VOSviewer apresenta nominalmente os autores com maior número de publicações em determinados períodos. A Figura 4, a seguir, apresenta a rede de autores por ano de publicação dos artigos.

Figura 4 - Rede de autores por ano.

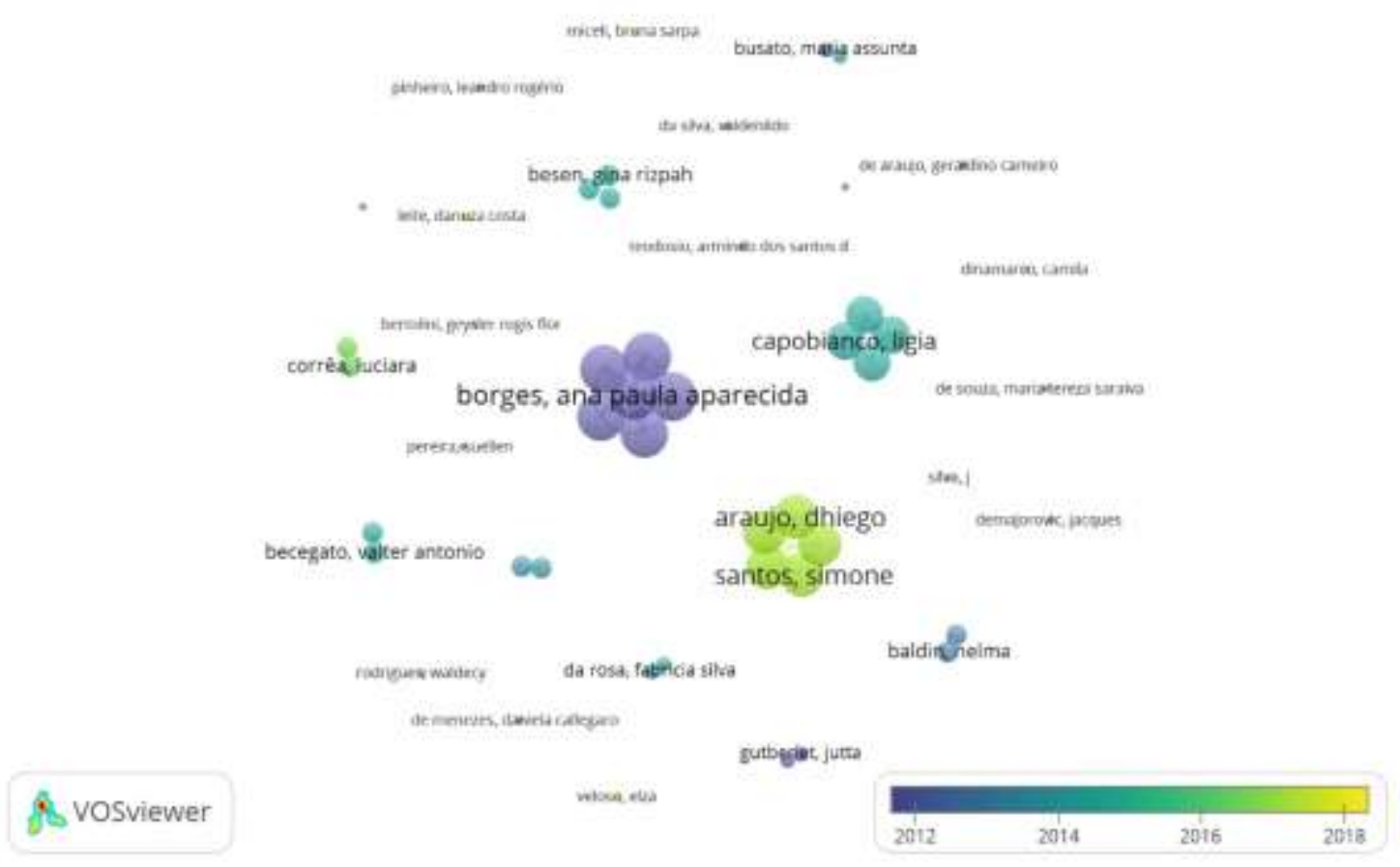

Fonte: Dados da pesquisa (2021).

A barra de cores (Figura 4) demonstra o impacto das publicações no decorrer dos últimos anos, sendo que os de cores mais escuras (azul) são de datas mais antigas e à medida que as cores vão ficando mais claras (amarelo), referem-se as publicações recentes. Observado os critérios de Van Eck e Waltman (2010), o cluster formado por Borges publicou mais em períodos mais antigos, seguido por Capobianco e, mais recentemente, Araújo e Santos.

De acordo com a pesquisa e análise dos artigos encontrados, as 15 principais revistas do país que publicaram sobre o tema "Coleta Seletiva", estão ordenados no Quadro 1. Importante ressaltar que os demais artigos dos 199 com PDFs selecionados estão publicados em revistas que apresentam pelo menos 1 artigo. Relevante mencionar que os autores dos artigos, são de Universidades e entidades de todo país. 
Quadro 1: Quadro 1: Revistas que mais publicaram sobre o tema.

\begin{tabular}{|l|l|}
\hline Revistas & Publicações \\
\hline Revista Monografias Ambientais & 26 \\
\hline Brazilian Journal of Management / Revista de Administracao da UFSM & 8 \\
\hline Revista de Gestao Ambiental e Sustentabilidade / UNINOVE & 7 \\
\hline Universidade de Sao Paulo & 6 \\
\hline Universidade Estadual do Centro-Oeste, Setor de Ciencias Sociais Aplicadas & 4 \\
\hline Revista Ciência e Natura & 3 \\
\hline Iberoamerican Journal of Industrial Engineering & 2 \\
\hline Demetra: Food, Nutrition \& Health / Alimentação, Nutrição \& Saúde & 2 \\
\hline Sustinere & 2 \\
\hline Instituto Socioambiental Arvore & 2 \\
\hline Revista UniVap & 2 \\
\hline Routledge & 2 \\
\hline Pesquisa Brasileira em Odontopediatria e Clinica Integrada Journal (Brazil) & 2 \\
\hline Wiley-Blackwell & 2 \\
\hline Revista de Enfermagem UFPE & 2 \\
\hline
\end{tabular}

Fonte: Dados da pesquisa (2021).

O software Endnote possibilita verificar além das principais revistas que publicaram sobre o tema, ainda apresenta as cidades com periódicos e suas respectivas publicações sobre o tema "coleta seletiva". Na região sudeste, São Paulo e Rio de Janeiro são os estados que mais contribuem com publicações relacionadas a coleta seletiva. Entretanto, a região Sul também se destaca, além de que o Nordeste, mais precisamente o Estado do Rio Grande do Norte, em sua capital Natal, igualmente atribui importância ao tema.

Com os principais termos que resumem as informações encontradas nas pesquisas, a Tabela 1 apresenta as principais palavras encontradas na pesquisa, revelando as mais diversas áreas das ciências quanto ao termo, por exemplo: saúde pública, educação ambiental, gerenciamentos, meio ambiente, coleta seletiva, logística reversa, cooperativas, entre outras.

Tabela 1 - Principais palavras-chave.

\begin{tabular}{lcl}
\hline Palavras-chave & Quantidade & Porcentagem \\
\hline Brazil & 29 & 10,78 \\
Public health & 15 & 5,58 \\
Recycling & 15 & 5,58 \\
Environmental education & 14 & 5,20 \\
Solid waste & 14 & 5,20 \\
Sustainability & 13 & 4,83 \\
Resíduos Sólidos & 13 & 4,83 \\
Waste management & 11 & 4,09 \\
Reciclagem & 11 & 4,09 \\
Environmental Sciences & 10 & 3,72 \\
Coleta Seletiva & 10 & 3,72 \\
Sustainable development & 9 & 3,35 \\
Waste Disposal & 8 & 2,97 \\
Environmental Impact & 8 & 2,97 \\
Solid waste management & 8 & 2,97 \\
Environmental management & 8 & 2,97 \\
Educação Ambiental & 7 & 2,60 \\
Selective Collection & 7 & 2,60 \\
\hline
\end{tabular}




\begin{tabular}{lll}
\hline Logística Reversa & 7 & 2,60 \\
Meio Ambiente & 7 & 2,60 \\
Solid Waste Landfill & 6 & 2,23 \\
Management & 6 & 2,23 \\
Reverse Logistics & 6 & 2,23 \\
Catadores & 6 & 2,23 \\
Resíduos Sólidos Urbanos & 6 & 2,23 \\
Public Policies & 4 & 1,49 \\
Gestão Ambiental & 4 & 1,49 \\
Waste Pickers & 4 & 1,49 \\
Cooperatives & 3 & 1,12 \\
\hline
\end{tabular}

Fonte: Dados da pesquisa (2021).

Um fato relevante a ser observado, trata-se do termo cooperativa que aparece "apenas" 3 vezes. As cooperativas têm sido apontadas como uma ferramenta de transformação social para os catadores de materiais recicláveis. Via de regra esses trabalhadores estão desamparados por políticas públicas que possam auxiliar na integração social, portanto, as cooperativas podem ser importantes na mudança dos rumos desse coletivo.

Concernente ao número de publicações por ano, no período pesquisado a figura 5, expõem em quantidade o que foi publicado. Os temas de artigos que trata da coleta seletiva começaram a ganhar espaço. A partir do ano de 2006 , com 11 publicações, apresentou-se evolução considerável, onde atinge o pico no ano de 2015, com 72 artigos publicados e apresentam uma curva descendente nos anos seguintes.

O pico em 2015 refere-se com o não cumprimento da meta em extinguir os lixões, onde são depositados os resíduos sólidos sem nenhum tratamento, cujo prazo estava definido, na lei 12.305/2010, até o ano de 2014. Diversas pesquisas versaram sobre o tema e apresentaram as questões precárias em todo Brasil. Os prazos foram prorrogados posteriormente até o ano de 2021 para as capitais; para o ano de 2022 às cidades com mais de 100.000 habitantes; cidades de 50.000 a 100.000 habitantes para o ano de 2023; e para 2024 as cidades com menos de 50.000 mil habitantes (Lei 14.026, 2020).

Figura 5 - Número de publicações por ano.

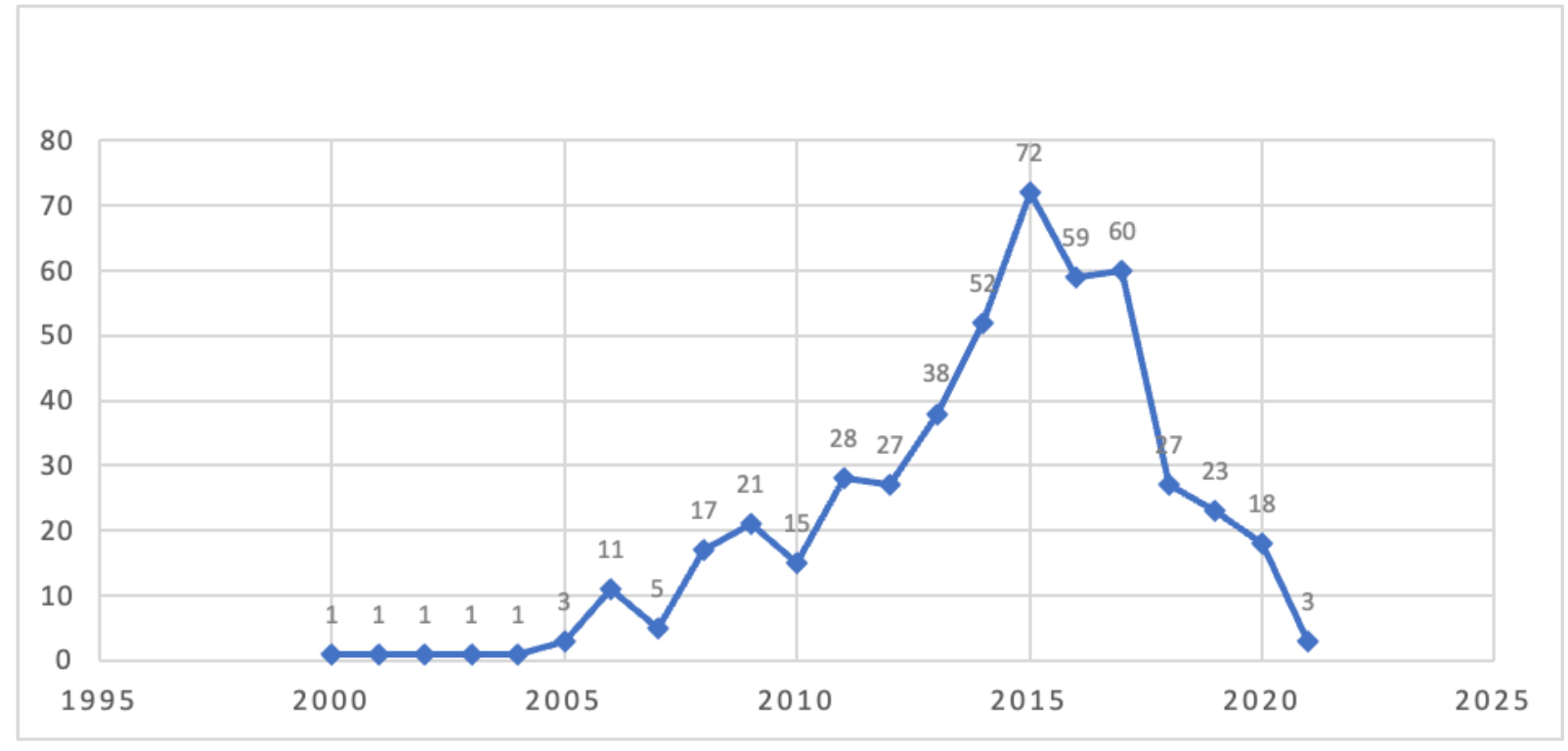

Fonte: Dados da pesquisa (2021). 
A evolução temporal de publicações com a temática concentrou-se nos anos de 2013 a 2017, havendo um declínio expressivo para 2018, sendo que apresenta a mesma tendência para os anos de 2019 e 2020. O ano de 2021, apesar de haver 3 publicações, ainda não é possível descrever, portanto, não cabendo análise parcial para este ano.

É um alerta importante para as ações e estratégias na esteira dos resíduos sólidos e dos catadores de materiais recicláveis, já que os municípios geralmente têm deixado a desejar na implementação destas políticas públicas. As universidades e pesquisadores normalmente são os apoiadores e articuladores dessas iniciativas, e que usualmente são alinhados e defensores da economia solidária, sendo assim a redução de estudos acende a luz de alerta para o tema.

\section{Considerações Finais}

Dentro do universo da pesquisa em relação aos artigos publicados, observa-se um cenário de crescimento da coleta seletiva no Brasil, em que pese ainda ter espaço significativo para avanços. A coleta seletiva, no ano de 2002 , atingia 129 toneladas de materiais, ao passo que em 2017, o volume atingiu 1,5 milhões de toneladas. Porém, se comparados com os resíduos sólidos, observa-se diferença relevante, pois em 2017 o parâmetro apresentava uma média per capita de 0,95kg/hab/dia ou 347kg/hab/ano para os resíduos sólidos, enquanto a massa de recicláveis foi de apenas 13,7 kg/hab/ano.

Considerando que o artigo objetivou apresentar o estado da arte a respeito da coleta seletiva de materiais recicláveis no Brasil, por meio de uma análise bibliométrica, destaca-se a concentração das publicações na região Sul e Nordeste do país. Quanto a evolução das publicações, o pico foi o ano de 2015, apresentando uma queda para os anos subsequentes.

A amostra dos journals não considerou o fator de impacto e nem foi observado Qualis periódicos, apenas o quantitativo das publicações. A maior quantidade ficou concentrada em poucas revistas, porém com grande diversidade de publicações em todo país. Na mesma tendência, também não houve concentração de autores, identificando-se diversos clusters, sendo o principal com seis autores.

As principais palavras-chave encontradas nos materiais pesquisados, revelam o interesse de diversas áreas do conhecimento sobre o tema. As mais destacadas são: Públic health, environmental, sustainability, resíduos sólidos, waste management, reciclagem, environmental sciences, coleta seletiva, sustainable development, logística reversa, cooperativas, entre outros. Os destaques também apresentam correlação aos dispositivos da lei 12.305 de 2010.

Os pesquisadores do tema coleta seletiva, usualmente tem apresentado e relatado os casos que sucedem em todo o Brasil, validando o que na prática vem se revelando como ações significativas, em que pese a falta de interesse dos municípios em apoiar concretamente com políticas públicas.

O uso de políticas públicas poderia estimular mecanismos que possibilite a promoção da sustentabilidade, desenvolvimento econômico e social na economia local, gerando maiores possibilidades as cooperativas ou associação de catadores de materiais recicláveis, contribuindo na geração de trabalho e renda das famílias e reduzindo o passivo ambiental, decorrentes da ineficácia do tratamento e destinação dos resíduos produzidos nas cidades.

Um destaque importante e preocupante da pesquisa foi o baixo índice de menções ao termo cooperativa, pois diante da vertente neoliberal na política e na condução da economia do país, o cooperativismo apresenta-se como uma alternativa que pode resguardar essas pessoas de condições insalubres dos lixões, alçando a melhores condições de vida no aspecto social, pois inevitavelmente poderá gerar trabalho e renda a esse coletivo de excluídos, sem contar que promovem um modelo sustentável que gera benefício ao homem e ao meio ambiente.

Como sugestões de pesquisas futuras, levantar o estado da arte de temas específicos como logística reversa e aterros sanitários, pois estão impostos nos preceitos da lei 12.305 de 2010, e são essenciais ao bem-estar das pessoas e saúde do planeta. Necessário ainda a realização de estudos mais aprofundados no marco regulatório do saneamento básico, referente a 
lei 14.026/2020, que amplia o prazo para extinção dos lixões, concessões de serviços básicos e principalmente no tocante as metas de universalização dos serviços públicos de saneamento básico.

\section{Referências}

Lei n 12.305, de 02 de agosto de 2010. (2010). Institui a Política Nacional de Resíduos Sólidos; altera a Lei no 9.605 , de 12 de fevereiro de 1998 ; e dá outras providências. Presidência da República.

Lei n ${ }^{\circ} 14.026$, de 15 de julho de 2020. (2020). Atualiza o marco legal do saneamento básico e altera a Lei $n^{\circ} 9.984$, de 17 de julho de 2000 , para atribuir à Agência Nacional de Águas e Saneamento Básico (ANA) competência para editar normas de referência sobre o serviço de saneamento, a Lei ${ }^{\circ}{ }^{10.768, ~ d e ~} 19$ de novembro de 2003, para alterar o nome e as atribuições do cargo de Especialista em Recursos Hídricos, a Lei n 11.107 , de 6 de abril de 2005, para vedar a prestação por contrato de programa dos serviços públicos de que trata o art. 175 da Constituição Federal, a Lei ${ }^{\circ} 11.445$, de 5 de janeiro de 2007 , para aprimorar as condições estruturais do saneamento básico no País, a Lei $\mathrm{n}^{\circ} 12.305$, de 2 de agosto de 2010, para tratar dos prazos para a disposição final ambientalmente adequada dos rejeitos, a Lei $\mathrm{n}^{\mathrm{o}}$ 13.089, de 12 de janeiro de 2015 (Estatuto da Metrópole), para estender seu âmbito de aplicação às microrregiões, e a Lei $n^{\circ} 13.529$, de 4 de dezembro de 2017, para autorizar a União a participar de fundo com a finalidade exclusiva de financiar serviços técnicos especializados. Presidência da República.

Besen, G. R., Ribeiro, H., Gunther, W. M. R., \& Jacobi, P. R. (2014). Selective waste collection in the São Paulo Metropolitan Region: impacts of the National Solid Waste Policy. Ambiente \& Sociedade. 17(3). https://doi:10.1590/S1414-753X2014000300015.

Bringhenti, J. (2004). Coleta Seletiva de Resíduos Sólidos Urbanos: Aspectos Operacionais e da Participação da População. [Tese de Doutorado, Faculdade de Saúde Pública da Universidade de São Paulo].

Cempre - Compromisso Empresarial (2013). Para Reciclagem. 2013. http://www. cempre. org.br

Conke, L.S., \& Nascimento, E. P. (2018). A coleta seletiva nas pesquisas brasileiras: uma avaliação metodológica. URBE. Revista Brasileira de Gestão Urbana. 10(1), 199-212. https://doi:10.1590/2175-3369.010.001.ao14.

Silva, G. R., \& Zanin, M. (2017). Catadores e movimento social: uma pesquisa bibliométrica. Revista Digital Biblioteconomia e Ciência da Informação. 15(1), $07-13$.

Gutierrez, R. F., \& Zanin, M. (2011). Empreendimentos econômicos de catadores de resíduos e legislações vigentes: avanços e limites. Gerais: Revista Interinstitucional de Psicologia, 4, 113-121.

Megid Neto, J. (2009). Educação ambiental como campo de conhecimento: a contribuição das pesquisas acadêmicas para sua consolidação no Brasil. Pesquisa em Educação Ambiental. 4(2), 95-110. https://doi.org/10.18675/2177-580X.vol4. n2.p95-110.

Mena-Chalco, J. P., \& Junior, C. (2013). Prospecção de dados acadêmicos de currículos Lattes através de Scriptlattes. Bibliometria e Cientometria: reflexões teóricas e interfaces.

Ministério do Desenvolvimento Regional (2019). Sistema Nacional de Informações sobre Saneamento:Diagnóstico do Manejo de Resíduos Sólidos Urbanos 2017. 194 p.

Miranda, N. M., \& Mattos, U. A. O. (2018). Revisão dos Modelos e Metodologias de Coleta Seletiva no Brasil. Sociedade e Natureza, 30(2), 1-22.

Movimento Nacional dos Catodres de Materiais Recicláveis (2019). História do MNCR. http://www.mncr.org.br/sobre-o-mncr/sua-historia

Moraes, F. G. A. (2011) Autogestão e participação na cadeia produtiva. É possível? Revista Geográfica de América Central. Número Especial EGAL1.

Oliveira, S. C. M., Barbosa, E. de S., Rezende, I. C. C., Silva, R. P. A., \& Albuquerque, L. S. (2013). Bibliometria em artigos de contabilidade aplicada ao setor público. Anais Do Congresso Brasileiro De Custos - ABC. https://anaiscbc.emnuvens.com.br/anais/article/view/125

Pereira, M. C. G., \& Teixeira, M. A. C. (2011). A inclusão de catadores em programas de coleta seletiva: da agenda local à nacional. Cadernos EBAPE.BR. 9(3), 895-913. https://doi:10.1590/S1679-39512011000300011.

Richardson, R. J., Peres, J. A.S., Wanderley, J. C. V., Correia, L. M., \& Peres, M. H. M. (2012). Pesquisa Social Métodos e Técnicas. (3a ed.), Atlas.

Silva, E. L., \& Menezes, M. M. (2005). Metodologia da pesquisa e elaboração de dissertação. (4a ed.), Laboratório de Ensino à Distância da UFSC. 138 p.

Tranfield, D., Denyer, D., \& Smart, P. (2003) . British journal of management. Towards a methodology for developing evidence-informed management knowledge by means of systematic review. 14(3), 207-222.

Van Eck, N. J., \& Waltman, L. (2010) .Software survey: VOSviewer, a computer program for bibliometric mapping. Scientometrics. 84(2), 523-538. https://doi:10.1007/s11192-009-0146-3. https://www.ncbi.nlm.nih.gov/pubmed/20585380.

Yamakawa, E. K., Kubota, F. I., Beuren, F. H., Scalvenzi, L., \& Miguel, P. A. C. (2014). Comparativo dos softwares de gerenciamento de referências bibliográficas: Mendeley, EndNote e Zotero. Transinformação. 26(2), 167-176. https://doi:10.1590/0103-37862014000200006. 